\section{Cureus}

Received 10/08/2019

Review began 10/10/2019

Review ended 10/20/2019

Published 10/22/2019

\section{(c) Copyright 2019}

Al Mulhim et al. This is an open access article distributed under the terms of the Creative Commons Attribution License CC-BY 3.0., which permits unrestricted use, distribution, and reproduction in any medium, provided the original author and source are credited.

\title{
Dignitary Medicine: A Novel Area of Medical Training
}

Mobarak A. Al Mulhim ${ }^{1}$, Robert G. Darling ${ }^{2}$, Hetaf Kamal ${ }^{3}$, Amalia Voskanyan ${ }^{3}$, Gregory Ciottone $^{3}$

1. Emergency Medicine, Beth Israel Deaconess Medical Center, Boston, USA 2. Emergency Medicine, Uniformed Services University of the Health Sciences, Bethesda, USA 3. Emergency Medicine, Beth Israel Deaconess Medical Center, Boston, USA

$\square$ Corresponding author: Mobarak A. Al Mulhim, kfshed@gmail.com

\section{Abstract}

Dignitary medicine (DM) involves the provision of healthcare to government leaders and other high-profile individuals collectively referred to as "dignitaries." Due to the unique circumstances around their lifestyle, dignitaries often receive suboptimal healthcare. We define the requisite skills needed to practice DM based on the available literature and provide a framework for training providers in these skills.

A review of the English language medical literature focussing on adult subjects was performed, searching for terms such as "dignitary medicine," "VIP medicine," and "protective medicine." Literature was gathered from CINAHL, Google Scholar, PubMed, EBSCOHost, and San Bernardino County Library databases and then analyzed by experienced DM providers.

A total of 23 relevant articles were eligible for review. No meta-analyses on the subject exist. We found that existing studies highlight skills in wellness, executive health, and protective medicine, which form the backbone of DM.

The burgeoning field of DM encompasses several disciplines and skills. We strongly recommend a structured curriculum for the field of DM, focused on dignitary wellness, executive health, and protective medicine.

Categories: Miscellaneous, Emergency Medicine, Medical Education

Keywords: dignitary medicine, presidential health, curriculum development research, concierge medicine, vip, protective medicine, emergency medicine, curriculum, curriculum development

\section{Introduction And Background}

Dignitaries are a select group of high-profile politicians, royal family members, and businessmen. While similar to celebrities, athletes, and musicians, dignitaries are not only famous, but their health can impact the political and economic health of a city, nation, or even the world. As such, dignitaries have a unique set of healthcare needs, which the general public does not have [1]: they require aggressive preventive and protective medical care, 24/7 highquality personalized healthcare, and an even greater degree of privacy than ordinary citizens. International travel, especially as part of humanitarian or political missions, can create novel exposures to infections or illnesses. Medical and transportation infrastructure may be primitive on many trips, creating logistical challenges the medical team must plan for and overcome [1]. Threats of assassination add another layer of concern for dignitaries. The average person traveling on a business trip will be well-suited to receive emergency care at a local ED; however, 
if the president of a nation merely arrives in an emergency department (ED) and is not properly cared for, an international calamity may ensue. Communication with the press, media, and public about the condition of a dignitary takes on an added dimension, which average patients just do not require. Furthermore, privacy is of even greater concern for dignitaries than the average patient.

Dignitaries often have a close circle of advisors and confidants that limit or hinder the doctorpatient relationship [2]. The power, prestige, and station that a dignitary has may result in some providers being awestruck and not providing the same advice or treatment suggestions as to a non-dignitary patient [3]. A dignitary may be a critical member of an international delegation and illness may threaten the purpose of an international business or political trip. On the flip side, dignitaries often receive worse care than the average patient because doctors and care teams may disrupt the normal and smooth flow of clinical operations to handle such patients [2]. Furthermore, the "Chairperson Syndrome" [2] may emerge, where the most senior members of a department may insert themselves into the care team while other members of the team may be better suited and skilled to manage the clinical issues at hand. The complex schedules and demands on dignitaries also make providing care a challenge.

To combat the deficiencies in the care provided to dignitaries, we propose a novel field of medical training, "Dignitary Medicine" (DM), and offer suggestions on the core competencies of DM trainees. We analyzed the existing literature to inform the needed training and competencies and report the results of our investigation herein.

\section{Review}

A unstructured review of the English language medical literature focused on adult subjects was performed. The source of information involved collecting data from EMBASE, CINAHL Plus (Cumulative Index of Nursing and Allied Health Literature Plus), Cochrane Library, PubMed, Google Scholar, Global Health Library, SBC Library (San Bernardino County Library), and EBSCO Host (Elton B Stephens Company Host) databases. The databases were searched for the terms "dignitary medicine," "executive health," "concierge medicine," "protective medicine," "royal health," "presidential health," "royal physicians," "presidential physician," "the WHMU” and "the royal clinics." Furthermore, two books "When Illness Strikes the Leader" written by Post \& Robins in 1995 and "The White House Physician: A History from Washington to George W. Bush," written by McFarland Deppisch in 2007 were evaluated. Institutional review board (IRB) approval was not needed, as human subjects were not involved in this project.

The inclusion criteria included articles reviewed in English and published in peer-reviewed journals. The articles included dignitaries as a patient population, their respective physicians, or practice related to those populations. Articles addressing politics, news reports, advertisements, and health care professionals other than a physician were excluded.

Two team members reviewed each of the abstracts and the related titles. Studies that were marked for potential inclusion by both reviewers underwent a full-text review by two separate team members. If we agreed that a given study did not merit inclusion, the study was excluded. In instances where the reviewers did not agree, the disagreement was resolved through consensus and discussion with additional team members.

We extracted the following information from the potential articles: publication details (authors, publication type, title, journal, volume, issue, page numbers, publication location, and digital object identifier (DOI)); study details (timeframe, location of study, and study design); participant information (source population, definition of the target, target population size, and source of population size); and other salient data (interventions, the core skills of DM, and best principles). 


\section{Cureus}

We found 2039 articles in our initial search but most were of poor quality and did not meet inclusion criteria (Figure 1). We only found 23 articles at the end of our search string that met inclusion criteria. Based upon our review of the included studies, we identified four recurring themes in the literature: executive health, protective medicine, overall health/wellness, and leadership/professionalism/ communication (Table 1). The existing literature covers these skills, with an emphasis on executive health and protective medicine, with several studies focusing on specific events such as the attempted assassination of President Reagan.
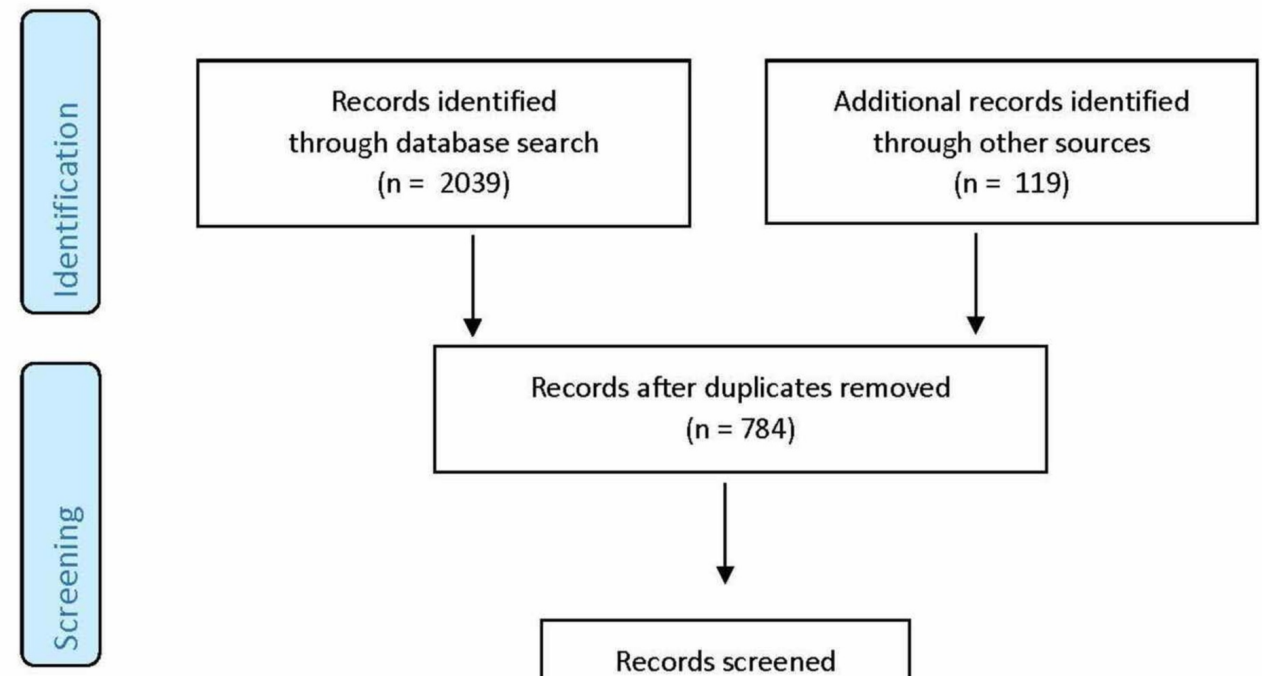

( $n=784)$

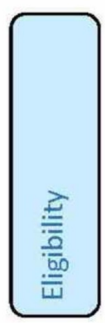

Records screened

$(n=248)$

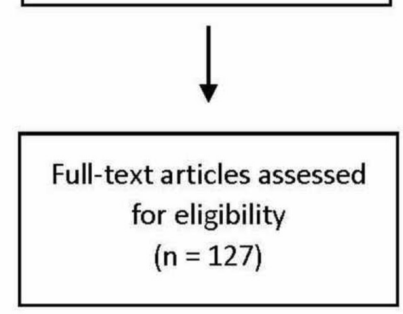

Studies analyzed

$(n=23)$

FIGURE 1: Search strategy and flowchart

\section{Author}

Aaron et al [4]

Ahmed et al [5]

Alfandre et al [6]
Study

Population

1994 US President

2018 US President

2016 VIP's
Key Finding

Emphasis on ready access to specialty care

Treating the VIP the same as other patients

Treating the VIP the same as other patients
Skill

Areas

$\mathrm{EH}, \mathrm{PH}, \mathrm{L}$

$\mathrm{EH}, \mathrm{L}$

EH, L 


\section{Cureus}

\begin{tabular}{|c|c|c|c|c|}
\hline Band et al [1] & 2012 & VIP's & Emphasis on pre-hospital and tactical skills & $\mathrm{PH}$ \\
\hline Block at al [7] & 1993 & VIP's & $\begin{array}{l}\text { Awareness of treating VIP's differently than other } \\
\text { patients }\end{array}$ & $\mathrm{EH}, \mathrm{L}$ \\
\hline Dalen at al [8] & 2017 & $\begin{array}{l}\text { Concierge } \\
\text { Practice }\end{array}$ & Basics of concierge medicine & $\mathrm{EH}$ \\
\hline Diekma [9] & 2000 & VIP's & Approach to VIP patients in the ED & $\mathrm{EH}$ \\
\hline Diekma [10] & 1996 & VIP's & Approach to VIP patients in the ED & $\mathrm{EH}$ \\
\hline Eddy [11] & 2016 & Healthcare teams & Best practices for healthcare teams & $\mathrm{L}$ \\
\hline Edlich et al [12] & 2004 & US President & Emergency medical systems & $\mathrm{PH}$ \\
\hline Feuer et al [3] & 1978 & VIP's & Impact of VIP's on a medical team & $\mathrm{EH}, \mathrm{L}$ \\
\hline Friedman [13] & 1995 & US President & Disability and the US president & W \\
\hline Groves et al [14] & 2002 & VIP's & Psychiatric care of VIP's & $\mathrm{EH}, \mathrm{W}$ \\
\hline Guzman et al [2] & 2011 & VIP's & Nine key principles to managing VIP patients & $\mathrm{EH}, \mathrm{L}$ \\
\hline Lerner [15] & 2001 & First Lady & Eleanor Roosevelt and a possible missed diagnosis & $\mathrm{EH}, \mathrm{W}$ \\
\hline Mahmood et al [16] & 2014 & Physician patients & Framingham Heart Study & W \\
\hline Martin et al [17] & 2004 & VIP's & VIP psychiatric health & $\mathrm{EH}, \mathrm{W}$ \\
\hline $\begin{array}{l}\text { Schenkenberg et al } \\
\text { [18] }\end{array}$ & 2007 & VIP's & Ethics and VIP health & $\mathrm{EH}, \mathrm{L}$ \\
\hline Silverman et al [19] & 2012 & VIP's & VIP's and psychiatric care & $\mathrm{EH}, \mathrm{L}$ \\
\hline $\begin{array}{l}\text { Smith and Shesser } \\
\text { [20] }\end{array}$ & 1988 & VIP's & Emergency care of VIP's & $\mathrm{EH}, \mathrm{P}$ \\
\hline Strange [21] & 1980 & VIP's & VIP's with illness & $\mathrm{EH}, \mathrm{P}$ \\
\hline Weintraub [22] & 2012 & VIP's & VIP's and mental health & $\mathrm{EH}$ \\
\hline
\end{tabular}

\section{TABLE 1: Articles grouped by relevant DM skill grouping}
$\mathrm{EH}=$ Executive Health
$\mathrm{PH}=$ Protective Health
$L=$ Leadership
$\mathrm{W}=$ Wellness
$\mathrm{P}=$ Professionalism

To offer a broad and full-service array of medical services for dignitaries, as opposed to a 
fragmented approach delivered by a slew of specialists, we believe DM physicians need mastery of executive health, protective medicine, overall wellness, and, finally, professionalism, leadership, and communication (Figure 2). These four thematic areas emerged in the scant literature available for review on this topic and form a starting point for further curricular development and, potentially, training in this field. We further define these unique skills below.

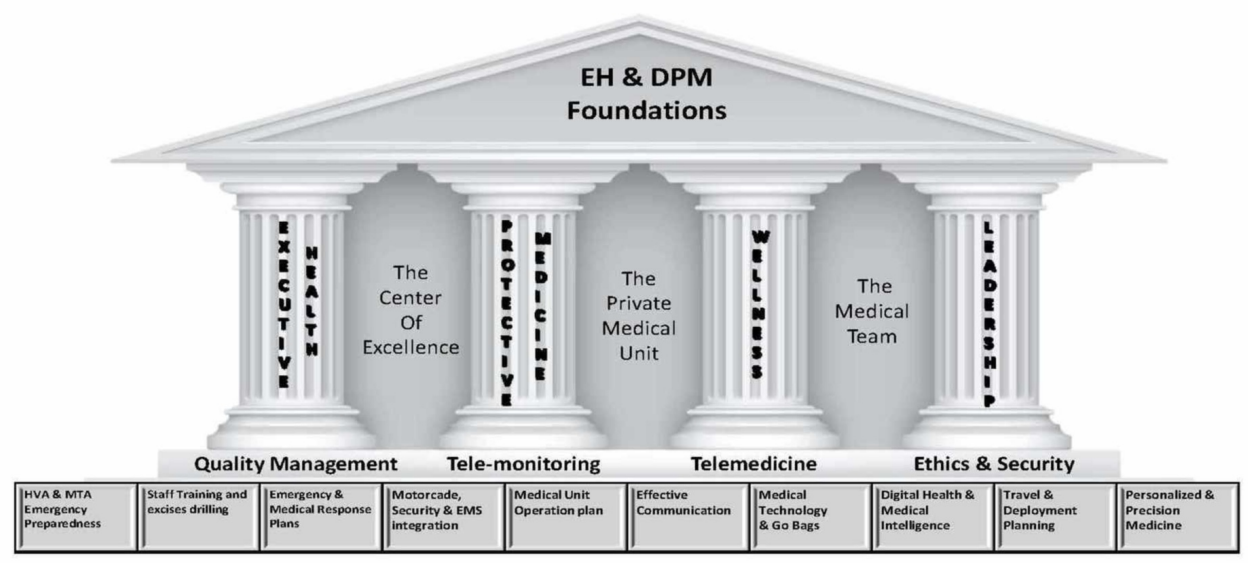

FIGURE 2: The foundations of dignitary medicine

Executive health refers to the general health maintenance of the dignitary, something akin to concierge medicine [23]. DM physicians provide some primary care but may also refer specific health matters to specialists in predesignated medical centers of excellence. The DM physician commonly establishes a "hotline" system by arranging immediate access to the best available specialty services and consultants around the world, with particular attention to medical record security and concierge access.

Protective medicine involves all protective, tactical, and emergency medical care for the dignitary, his or her immediate family, and entourage, with a strong focus on preventing injury, illness, and even assassination. Procedures related to delivering protective care during travel and alongside motorcade activity are essential aspects of protective medicine. To be the most effective, protective medical care requires high levels of risk assessment and mitigation procedures, utilizing the best security and intelligence resources in collaboration with the dignitary's other support services. As such, non-medical personnel, such as security forces and the administrative staff of the dignitary, are critical partners for successful protective medical care.

Wellness involves the overall health and wellbeing of the dignitary. The DM physician designs a personalized health care plan that promotes primary prevention, with the goal of increasing longevity and promoting an illness-free life. This requires utilizing the best available evidencebased practices, screenings, and lifestyle interventions.

The leadership of a complex, multi-disciplinary team is requisite in this role. The DM physician is expected to oversee a complex medical team, uphold the highest level of quality, and be abreast of and implement advances in the care of the dignitary. Further, communication with the media, other providers, politicians, and security staff is a critical aspect of the DM physician's role. Finally, a good DM physician leader exercises the utmost in professionalism in safeguarding the privacy of the medical affairs of the dignitary. 
Throughout history, dignitaries have found it challenging to receive high-quality healthcare while, at the same time, maintaining their unique requirements for security and privacy [24-25]. Both assassination and the natural death of a governmental leader can threaten stability within the countries they serve [5]. The societal disruptions caused by the deaths of President Harrison due to pneumonia, President Harding from myocardial infarction, and President Tayler from gastroenteritis, as well as the assassinations of Presidents Garfield, Kennedy, Lincoln, and McKinley, have led to the understanding that the President's health and protection has become a fundamental national security issue [26]. As such, the DM physician's role goes beyond that of a doctor and patient and is a factor in national and geo-political stability.

Additionally, with such a diverse array of issues that require expert medical care, it is clear the DM providers need specialized training and skills in order to best care for dignitaries. In some cases, victims of assassination may benefit from a DM physician skilled in protective medicine and trauma care. In the event of illness, secrecy around a dignitary's condition may have beneficial effects for the patient and society at large. These patients demand high-level security and confidentiality when being treated at a hospital and such skills will need to be taught to DM providers [27].

In addition, there are a number of key clinical principles that allow the optimal care of the dignitary while not becoming awestruck and maintaining professionalism [15]. Silverman and his colleagues present literature demonstrating that physicians assigned to dignitaries may fail to provide the desired healthcare services, owing to the pressure associated with the status of dignitaries [28]. He goes on to offer possible solutions, essentially suggesting the treatment team includes DM physicians [28].

It is essential that physicians and medical personnel tasked with the provision of healthcare to dignitaries are sufficiently trained. Such training aims to ensure that the physicians within this area of medicine are equipped with the necessary skills to provide for the wellbeing and protection of dignitaries from illness and other health threats. To accomplish this, several options exist, including post-residency specialized fellowship training. Training may also be achieved through practice standardization and development of a formal curriculum and guidelines for DM. This professionalization, as well as standardization of such healthcare models, will help in the provision of optimized, high-quality care to dignitaries and their family members.

\section{Conclusions}

This review shows that the existing literature on DM is fragmented and no single article synthesizes the required skills into one review. We believe our paper can serve as an excellent resource for providers in this field. Given the combination of skills needed to practice DM - executive health, protective medicine, wellness, and leadership - we believe this is a unique area of medical training and that this review can serve as the basis of future training.

\section{Additional Information}

\section{Disclosures}

Conflicts of interest: In compliance with the ICMJE uniform disclosure form, all authors declare the following: Payment/services info: All authors have declared that no financial support was received from any organization for the submitted work. Financial relationships: All authors have declared that they have no financial relationships at present or within the previous three years with any organizations that might have an interest in the submitted work. Other relationships: All authors have declared that there are no other relationships or activities that could appear to have influenced the submitted work. 


\section{Acknowledgements}

We would like to thank Peter L. Steinberg, MD (Beth Israel Deaconess Medical Center, Division of Urology, Department of Surgery) for assistance with editing and preparing the manuscript for publication.

\section{References}

1. Band RA, Callaway DW, Connor BA, Haughton BP, Mechem CC: Dignitary medicine: adapting prehospital, preventive, tactical and travel medicine to new populations. Am J Emerg Med. 2012, 30:1274-1281. 10.1016/j.ajem.2011.10.019

2. Guzman JA, Sasidhar M, Stoller JK: Caring for dignitaries: nine principles. Cleve Clin J Med. 2011, 78:90-94. 10.3949/ccjm.78a.10113

3. Feuer Eh, Karasu SR: A star-struck service: impact of the admission of a celebrity to an inpatient unit. J Clin Psychiatry. 1978, 10:743-746.

4. Aaron Bl, Rockoff Sd: The attempted assassination of President Reagan. Medical implications and historical perspective. JAMA. 1994, 21:1689-1693.

5. Ahmed AK, Martinez-Del-Campo E, Theodore N: Daniel Ruge: the first neurosurgeon to serve as physician to the president. J Neurosurg. 2018, 1:1-7.

6. Alfandre D, Clever S, Farber NJ, Hughes MT, Redstone F, Lehmann LS: Caring for `very important persons'-ethical dilemma and suggestions for practical management. Am J Med. 2016, 129:143-147. 10.1016/j.amjmed.2015.09.019

7. Block AJ: Beware of the VIP syndrome. Chest. 1993, 104:989. 10.1378/chest.104.4.989b

8. Dalen JE, Alpert JS: Concierge medicine is here and growing!! . Am J Med. 2017, 130:880-881. 10.1016/j.amjmed.2017.03.031

9. Diekema DS: It's wrong to treat VIPs better than other patients . ED Manag. 2000, 12:92-93.

10. Diekema DS: The preferential treatment of VIPs in the emergency department . Am J Emerg Med. 1996, 14:226-229. 10.1016/S0735-6757(96)90137-0

11. Eddy K, Jordan Z, Stephenson M: Health professionals' experience of teamwork education in acute hospital settings: a systematic review Of qualitative literature. JBI Database Syst Rev Implement. 2016, 14:96-137. 10.11124/Jbisrir-2016-1843

12. EdlichRf, Winters K, Gebhart J: Saving President Reagan's life. The need for an organized emergency medical system in the United States to save lives of all casualties. J Long Term Eff Med Implants. 2004, 14:369-374.

13. Friedman RA: Presidential disability and the twenty-fifth amendment. JAMA. 1995, 274:797798. 10.1001/jama.1995.03530100037025

14. Groves JE, Dunderdale BA, Stern TA: Celebrity patients, VIPs, and potentates. Prim Care Companion J Clin Psychiatry. 2002, 4:215-223. PMID: 15014712; Pub Med Central PMCID: PMC315491

15. Lerner BH: Revisiting the death of Eleanor Roosevelt: was the diagnosis of tuberculosis missed?. Int J Tuberc Lung Dis. 2001, 5:1080-1085.

16. Mahmood SS, Levy D, Vasan RS, Wang TJ: The Framingham Heart Study and the epidemiology of cardiovascular disease: a historical perspective. Lancet. 2014, 9921:20132029. 10.1016/S0140-6736(13)61752-3

17. Martin A, Bostic JQ, Pruett K: The v.I.p.: hazard and promise in treating "special" patients . J Am Acad Child Adolesc Psychiatry. 2004, 43:366-369. 10.1097/00004583-200403000-00020

18. Schenkenberg T, Kochenour NK, Botkin JR: Ethical considerations in the clinical care of the "VIP". J Clin Ethics. 2007, 18:56-63.

19. Silverman BC, Asby A, Brendel DH, et al.: Psychiatric treatment of the VIP: some paradoxical risks. J Nerv Ment Dis. 2012, 200:545-548. 10.1097/NMD.0b013e318257c805

20. Smith MS, Shesser RF: The emergency care of the VIP patient. N Engl J Med. 1988, 319:14211423.

21. Strange RE: The VIP with illness. Mil Med. 1980 Jul, 145:473-475.

22. Weintraub W: The VIP syndrome: a clinical study in hospital psychiatry. 1964 . J Nerv Ment Dis. 2012, 200:457-469.

23. Cascardo D: Concierge medicine: is it becoming mainstream? Part II. Steps to developing a concierge practice. J Med Pract Manage. 2014, 30:176-179.

24. Case N: The dual-diagnosis patient in a psychiatric day treatment program: a treatment 


\section{Cureus}

failure. J Subst Abuse Treat. 1991, 8:69-73.

25. Beck RS, Daughtridge R, Sloane PD: Physician-patient communication in the primary care office: a systematic review. J Am Board Fam Pract. 2002, 15:25-38.

26. Berlin J: "The future" of pain treatment?. Tex Med. 2018, 114:38-42.

27. Goonan KJ, Muzikowski J: Baldrige: myths and realities. Hosp Health Netw. 2008, 5:84-85.

28. Sotos J: Presidential disability and the twenty-fifth amendment. JAMA. 1995, 274:799. 